\title{
PEDAGOGIA DA NATAÇÃO: ANÁLISE DAS ATIVIDADES REALIZA- DAS EM AULAS PARA CRIANÇAS ${ }^{1}$
}

\author{
Júlia Mello Fiori \\ Universidade Federal do Rio Grande do Sul, Porto Alegre, Rio Grande do Sul, Brasil. \\ Flávio Antônio de Souza Castro \\ Universidade Federal do Rio Grande do Sul, Porto Alegre, Rio Grande do Sul, Brasil. \\ Luísa Beatriz Trevisan Teixeira \\ Universidade Federal do Rio Grande do Sul, Porto Alegre, Rio Grande do Sul, Brasil. \\ Rossane Trindade Wizer \\ Universidade Federal do Rio Grande do Sul, Porto Alegre, Rio Grande do Sul, Brasil.
}

\begin{abstract}
Resumo
Considerando a importância da diversidade de experiências motoras aquáticas para a melhor relação do indivíduo com o ambiente, o presente estudo teve como objetivo analisar as atividades realizadas na iniciação de crianças à natação. Ao longo deste estudo foram identificadas e analisadas as atividades propostas por professores em 36 aulas, observadas de modo sistemático. Dentre os resultados, das 36 aulas de 8 professores, 33 continham atividades de técnicas de nado, em um total de 86 exercícios somados e realizados 134 vezes. Conclui-se que há a necessidade de se repensar a pedagogia da natação, pois a predominância no cenário atual é o ensino técnico dos quatro estilos competitivos antes mesmo do indivíduo se tornar independente e demonstrar competência no meio aquático.

Palavras-chave: desenvolvimento infantil, aprendizagem, natação, processo ensinoaprendizagem
\end{abstract}

\section{SWIMMING PEDAGOGY: ANALYSIS OF CLASS ACTIVITIES FOR CHILDREN}

\begin{abstract}
Considering the importance of the diversity of aquatic motor experiences for the best relationship between the subject and the environment, the present study aimed to analyze the activities performed in the initiation of children to swimming. Throughout this study, the activities proposed by teachers in 36 classes observed in a systematic way were identified and analyzed. Among the results, of the 36 classes, of eight teachers, 33 contained swimming technique activities, in 86 exercises added and performed 134 times. It is concluded that there is a need to rethink the pedagogy of swimming, because the predominance in the current scenario is the technical teaching of the four competitive strokes, before the individual becomes independent and demonstrate competence in the aquatic environment.
\end{abstract}

Key-words: Child development, learning, swimming, teaching-learning process

$1 \mathrm{O}$ presente trabalho não contou com apoio financeiro de nenhuma natureza para a sua realização. 


\section{PEDAGOGÍA DE LA NATACIÓN: ANÁLISIS DE LAS ACTIVIDADES REALIZA- DAS EN CLASES PARA NIÑOS}

\section{Resúmen}

Considerando la importancia de la diversidad de experiencias motoras acuáticas para la mejor relación del individuo con el ambiente, el presente estudio tuvo como objetivo analizar las actividades realizadas en la iniciación de niños a la natación. A lo largo de este estudio fueron identificadas y analizadas las actividades propuestas por profesores en 36 aulas observadas de modo sistemático. Entre los resultados, de las 36 aulas, de ocho profesores, 33 contenían actividades de técnica de nado, en un total de 86 ejercicios sumados y realizados 134 veces. Se concluye que hay la necesidad de repensar la pedagogía de la natación, pues la predominancia en el escenario actual es la enseñanza técnica de los cuatro estilos competitivos, antes de que el individuo se independice y demuestre competencia en el medio acuático.

Palabras-clave: Desarrolho infantil, aprendizaje, natación, proceso enseñanza-aprendizaje

\section{Introdução}

Quando um indivíduo entra em um ambiente aquático, se envolve com as forças daquele meio. Seu corpo está se relacionando com a água e se gerar propulsão suficiente para vencer o arrasto, está nadando, seja à superfície ou abaixo dela. Nadar pode ser entendido como se locomover de forma independente na água. Para nadar de forma segura e independente, este mesmo indivíduo precisa estar ambientado com o meio aquático, estabelecer relação segura entre o seu corpo e a água. Uma possibilidade de relacionamento com a água são as aulas de natação, formal ou competitiva (BURKHARDT; ESCOBAR, 1985). Porém, fazer natação, com o decorrer dos anos, assumiu o significado de utilizar-se das técnicas dos quatro estilos competitivos ( $\mathrm{crawl}$, costas, peito, golfinho) para deslocar-se na água (QUAN et al., 2015). Nas aulas de natação, os alunos inicialmente passam pela fase de adaptação ao meio aquático, e logo em seguida, são realizadas sequências pedagógicas para "aprender a fazer" os estilos convencionais, deixando em segundo plano a diversidade de experiências corporais aquáticas e focando nos conteúdos esportivos a serem desenvolvidos (FERNANDES; LOBO DA COSTA, 2006).

Muito além de dominar os movimentos da natação competitiva, é importante perceber as forças que atuam no meio aquático e, com isso, desenvolver estratégias autônomas para relacionar-se com o ambiente aquático em diferentes situações. Afinal, o ambiente aquático oferece uma infinidade de possibilidades, criando uma dimensão não programada de movimentos na relação corpo e meio. A locomoção aquática não depende somente das habilidades propulsivas, mas também da capacidade de redução do arrasto durante o nado (RIBEIRO, 2006). Para Langendorfer (2013), a habilidade de manter a postura e equilíbrio dentro da água é necessária para um nadador, além da relação com o arrasto, para conseguir trocar a posição do corpo em diferentes direções:

Antes de se questionar qual estilo aprender primeiro, nós deveríamos identificar qual habilidade aquática todos os nadadores precisam adquirir antes de considerar qual dos nados formais deve aprender. (LANGERDORGER, 2013, p. 288).

Considerando essas relações e, com base na literatura (CATTEAU; GAROFF, 1990; LANGERDORFER; BRUYA,1995; CANOSSA et al., 2007; XAVIER FILHO; MANOEL 2002; QUAN et al., 2015; CASTRO; CORREIA; WIZER, 2016), diversos conteúdos e ativi- 
dades são ou poderiam ser desenvolvidos em aulas de natação para crianças, como por exemplo:

(i) Atividades de técnicas/Educativos de nado e de saídas: o objetivo destas atividades é melhorar os estilos da natação esportiva competitiva ( $\mathrm{rrawl}$, costas, peito e golfinho). Segundo Xavier Filho e Manoel (2002), na natação, erros de performance são comparados a má realização técnica dos quatro estilos;

(ii) Atividades lúdicas: além da descontração e gosto pela prática, desenvolvem a competência aquática sugerida por Quan et al. (2015), que está relacionada com o conforto do indivíduo em se exercitar na superfície da água ou submerso;

(iii) Nados alternativos em relação aos quatro estilos competitivos ( $\mathrm{rawl}$, costas, peito e borboleta): trazem opções que fazem com que o indivíduo passe por situações não convencionais para deslocar-se. Os nados utilitários (nado cachorrinho, nado de aproximação ou marinheiro, nado lateral), os nados combinados (movimentos de membros superiores e de membros inferiores de diferentes nados, por exemplo: braçada do nado crawl com pernada do nado peito) e os nados em direção aos pés (inversão da propulsão: nado $c r a w l$ ao contrário na direção, por exemplo) são possibilidades de nados alternativos (CASTRO; CORREIA; WIZER, 2016);

(iv) Habilidades aquáticas gerais: desenvolvem a autonomia, a familiarização com o ambiente (CATTEAU; GAROFF, 1990) e formam a base para desenvolver outras habilidades motoras específicas (LANGERDORFER; BRUYA,1995). Atividades de equilíbrio, sustentação e flutuação estão presentes no conceito das habilidades aquáticas gerais. Segundo Reis (1987), nadadores que flutuam com mais naturalidade têm vantagem sobre os outros, já que a posição horizontal provoca menos resistência e auxilia o corpo a deslocar-se na água mais facilmente;

(v) Conteúdos de outros esportes aquáticos: uma das possibilidades de conteúdo, para além dos quatro estilos de nado, é utilizar elementos de outros esportes, como do polo aquático, da natação artística e dos saltos para a água, focando na competência aquática (CANOSSA et al., 2007). Um exemplo é a técnica de pernas para sustentação e deslocamento do polo aquático e da natação artística, chamada de egg-beater:

\begin{abstract}
Além de ser fundamental o desenvolvimento da habilidade do egg-beater para esses dois esportes aquáticos, sua técnica também deve ser considerada como uma importante competência aquática, pois se mostra eficaz no que diz respeito à sustentação do indivíduo em posição vertical na superfície e deslocamentos. (SILVA; GIULIANO; CASTRO, 2016, p.2, grifo nosso)
\end{abstract}

Além da pernada em egg-beater, e de acordo com Silva et al. (2016), o palmateio é uma técnica muito utilizada na natação artística e no polo aquático. É um movimento executado de forma simultânea pelos membros superiores, sendo um gesto tridimensional que desenha a figura de um oito ou uma forma oval. Utiliza-se o palmateio para sustentação e equilíbrio no meio aquático.

(vi) Deslocamentos variados: incentivam a criação de estratégias para enfrentar novas situações no meio aquático a partir das relações entre as forças de propulsão e de arrasto. A compreensão dos alunos sobre as forças do meio aquático auxilia a aprendizagem de novas formas de equilíbrio, respiração e propulsão no meio (CASTRO; CORREIA; WIZER, 2016). A propulsão pode ser gerada por formas diversas, além das pernadas e braçadas dos quatro estilos competitivos. Para Santos e Pereira (2008), a propulsão implica a completa adaptação humana 
ao meio aquático. Ainda, a capacidade de deslocar-se em imersão implica em uma série de conquistas relacionadas à imersão associada ao deslize.

Considerando as diversidades de movimentos no meio aquático, que possibilitam experiências corporais relacionadas ao desenvolvimento da postura e do equilíbrio corporal na água, surgiu o seguinte problema de pesquisa: "Uma concepção de nado para além dos quatro estilos está presente nas metodologias de ensino da natação na iniciação ao esporte em escolas de natação? Com o intuito de responder esta questão, o presente estudo tem como objetivo identificar e analisar as atividades realizadas na iniciação de crianças à natação, procurando problematizar o quanto professores trabalham visando o desenvolvimento de competências aquáticas diversas pelo aluno.

\section{Metodologia}

Esta pesquisa foi previamente aprovada pelo Comitê de Ética em Pesquisa da Universidade ao qual estava vinculado (número 69595617.8.0000.5347). Definiram-se os participantes de modo a representar os diferentes tipos de instituições que oferecem aulas de natação: escola privada, universidade, clube esportivo e projeto social. Participaram uma escola privada, uma ação de extensão de uma universidade, um projeto social e um clube. Foram entrevistados oito professores de seis turmas de natação infantil (alunos entre sete e dez anos de idade) que foram observados seis vezes cada ao longo de quatro semanas. Três professores eram formados em educação física e cinco ainda estavam em formação, mas já atuavam na área há, pelo menos, um ano.

Além dos conteúdos desenvolvidos, foram observadas também as estratégias utilizadas pelos professores durante as aulas. Posteriormente às observações, os professores foram questionados, em entrevista aberta, quanto aos objetivos de aula e como os desenvolvem. Após as entrevistas, as respostas dos entrevistados, registradas de modo escrito, foram revisadas pelos próprios a fim de confirmar suas intenções de resposta e corrigir qualquer detalhe. Os conteúdos e atividades investigados em relação a sua existência nas aulas, quantas vezes e como foram desenvolvidos foram:

(i) Atividades de técnicas/Educativos de nado e de saídas;

(ii) Atividades lúdicas;

(iii) Nados alternativos;

(iv) Habilidades aquáticas gerais;

(v) Conteúdos de outros esportes aquáticos, e

(vi) Deslocamentos variados.

Utilizou-se uma planilha que permitia registrar, para cada aula observada, o conteúdo/atividade, o número de vezes que era contemplado e como era desenvolvido. Feito isso, foram calculadas as frequências absolutas em relação ao número de aulas observadas de cada professor e em cada instituição.

\section{Resultados}

Os resultados são apresentados de forma quantitativa, por meio de tabelas com dados de frequências absolutas das atividades realizadas, e também qualitativas, por meio da descrição das atividades, características gerais e estratégias de ensino utilizadas. A Tabela 1 apre- 
senta o número de atividades diferentes que cada professor propôs em determinado tópico, quantas vezes as atividades desse tópico foram realizadas (podendo repetir em mais de uma aula) e em quantas aulas elas estiveram presentes.

Tabela 1 - Sumário quantitativo e comparativo das atividades observadas

\begin{tabular}{lccc}
\hline \multicolumn{4}{c}{ Professores "A" e "B" - ESCOLA DE NATAÇÃO DE UMA ACADEMIA } \\
\hline & $\begin{array}{c}\text { Número de } \\
\text { atividades }\end{array}$ & $\begin{array}{c}\text { Realizadas } \\
\text { quantas vezes }\end{array}$ & $\begin{array}{c}\text { Presente em } \\
\text { quantas aulas }\end{array}$ \\
\hline Técnica/Educativos de nado & 23 & 42 & 6 \\
Atividades Lúdicas & 5 & 12 & 6 \\
Nados Alternativos & 0 & 0 & 0 \\
Habilidades Aquáticas Gerais & 1 & 2 & 2 \\
Outros Esportes Aquáticos & 0 & 0 & 0 \\
Deslocamentos Variados & 3 & 8 & 5
\end{tabular}

\begin{tabular}{lccc}
\hline \multicolumn{4}{c}{ Professor “C" - ESCOLA DE NATAÇÃO DE UM CLUBE ESPORTIVO } \\
\hline \multicolumn{1}{c}{ Tópico } & $\begin{array}{c}\text { Número de } \\
\text { atividades }\end{array}$ & $\begin{array}{c}\text { Realizadas } \\
\text { quantas vezes }\end{array}$ & $\begin{array}{c}\text { Presente em } \\
\text { quantas aulas }\end{array}$ \\
\hline Técnica/Educativos de nado & 16 & 24 & 6 \\
Atividades Lúdicas & 4 & 8 & 6 \\
Nados Alternativos & 0 & 0 & 0 \\
Habilidades Aquáticas Gerais & 2 & 2 & 2 \\
Outros Esportes Aquáticos & 0 & 0 & 0 \\
Deslocamentos Variados & 3 & 3 & 2
\end{tabular}

\begin{tabular}{lccc}
\hline \multicolumn{4}{c}{ Professor “D” - ESCOLA DE NATAÇÃO DE UM CLUBE ESPORTIVO } \\
\hline & $\begin{array}{c}\text { Número de } \\
\text { Atividades }\end{array}$ & $\begin{array}{c}\text { Realizadas } \\
\text { quantas vezes }\end{array}$ & $\begin{array}{c}\text { Presente em } \\
\text { quantas aulas }\end{array}$ \\
\hline Técnica/Educativos de nado & 25 & 34 & 6 \\
Atividades Lúdicas & 6 & 8 & 5 \\
Nados Alternativos & 1 & 3 & 3 \\
Habilidades Aquáticas Gerais & 2 & 3 & 3 \\
Outros Esportes Aquáticos & 2 & 2 & 2 \\
Deslocamentos Variados & 6 & 10 & 4 \\
\end{tabular}

\begin{tabular}{lccc}
\hline \multicolumn{4}{c}{ Própessor “E” - PROJETO SOCIAL DE UM CLUBE ESPORTIVO } \\
\hline & $\begin{array}{c}\text { Número de } \\
\text { Atividades }\end{array}$ & $\begin{array}{c}\text { Realizadas } \\
\text { quantas vezes }\end{array}$ & $\begin{array}{c}\text { Presente em } \\
\text { quantas aulas }\end{array}$ \\
\hline Técnica/Educativos de nado & 6 & 8 & 5 \\
Atividades Lúdicas & 11 & 18 & 6 \\
Nados Alternativos & 0 & 0 & 0 \\
Habilidades Aquáticas Gerais & 5 & 15 & 6 \\
Outros Esportes Aquáticos & 0 & 0 & 0 \\
Deslocamentos Variados & 4 & 7 & 5
\end{tabular}




\begin{tabular}{|c|c|c|c|}
\hline \multicolumn{4}{|c|}{ Professores "F" e "G" - AÇÃO DE EXTENSÃO DE UMA UNIVERSIDADE } \\
\hline Tópico & $\begin{array}{l}\text { Número de Ati- } \\
\text { vidades }\end{array}$ & $\begin{array}{c}\text { Realizadas } \\
\text { quantas vezes }\end{array}$ & $\begin{array}{l}\text { Presente em } \\
\text { quantas aulas }\end{array}$ \\
\hline Técnica/Educativos de nado & 9 & 13 & 5 \\
\hline Atividades Lúdicas & 5 & 5 & 4 \\
\hline Nados Alternativos & 1 & 1 & 1 \\
\hline Habilidades Aquáticas Gerais & 4 & 6 & 3 \\
\hline Outros Esportes Aquáticos & 0 & 0 & 0 \\
\hline Deslocamentos Variados & 4 & 6 & 4 \\
\hline \multicolumn{4}{|c|}{ Professor “H” - AÇÃO DE EXTENSÃO DE UMA UNIVERSIDADE } \\
\hline Tópico & $\begin{array}{c}\text { Número de Ati- } \\
\text { vidades }\end{array}$ & $\begin{array}{c}\text { Realizadas } \\
\text { quantas vezes }\end{array}$ & $\begin{array}{l}\text { Presente em } \\
\text { quantas aulas }\end{array}$ \\
\hline Técnica/Educativo de nado & 7 & 13 & 5 \\
\hline Atividades Lúdicas & 6 & 12 & 5 \\
\hline Nados Alternativos & 0 & 0 & 0 \\
\hline Habilidades Aquáticas Gerais & 0 & 0 & 0 \\
\hline Outros Esportes Aquáticos & 0 & 0 & 0 \\
\hline Deslocamentos Variados & 7 & 9 & 4 \\
\hline
\end{tabular}

Fonte: Elaborado pelos autores, 2019.

Conteúdos e atividades são descritos na seguinte ordem: Atividades de Técnicas/Educativos de Nado, Atividades Lúdicas, Nados Alternativos, Habilidades Aquáticas Gerais, Outros Esportes Aquáticos, Deslocamentos Variados; Entrevistas com Professores.

Atividades de Técnica/Educativos de nado

A Tabela 2 sumariza os exercícios técnicos observados.

Tabela 2 - Exercícios técnicos visualizados nas aulas

\begin{tabular}{|c|c|}
\hline \multicolumn{2}{|c|}{ Crawl } \\
\hline \multicolumn{2}{|c|}{$\begin{array}{l}\text { Completo (com e sem nadadeiras); captura (executar o nado crawl parando sempre } \\
\text { um braço à frente a cada ciclo de braçadas); equilibrando argola nas costas, com res- } \\
\text { piração 2x1; alongado; com as mãos nas axilas; }\end{array}$} \\
\hline Membros inferiores & Membros superiores \\
\hline $\begin{array}{l}\text { Em posição de streamline (posição esten- } \\
\text { dida de todo o corpo, para deslize, "fle- } \\
\text { cha") }\end{array}$ & $\begin{array}{l}\text { Apenas braçada de crawl (com e sem } \\
\text { flutuador) }\end{array}$ \\
\hline Com os braços ao longo do corpo & $\begin{array}{l}\text { Crawl com um braço só (segurando a } \\
\text { prancha, segurando o palmar e seguran- } \\
\text { do o corrimão) }\end{array}$ \\
\hline Com uma mão na prancha & Braçadas com os cotovelos estendidos \\
\hline $\begin{array}{l}\text { Com as duas mãos na prancha (com e } \\
\text { sem nadadeira) }\end{array}$ & Braçadas tocando os dedos na cabeça \\
\hline Lateral com prancha & Braçadas arrastando os dedos na água \\
\hline $\begin{array}{l}\text { Com prancha fazendo a respiração lateral } \\
\text { Com espaguete }\end{array}$ & Braçadas tocando os dedos no quadril \\
\hline Com as mãos no corrimão & \\
\hline Com o professor puxando & \\
\hline
\end{tabular}




\section{Costas}

\begin{tabular}{|c|c|}
\hline \multicolumn{2}{|c|}{$\begin{array}{l}\text { Completo; fechando e abrindo as mãos; contando os dedos das mãos; equilibrando a } \\
\text { argola no rosto; }\end{array}$} \\
\hline Membros inferiores & Membros superiores \\
\hline Em posição de streamline & Braçada de costas em pé \\
\hline Com os braços ao longo do corpo & Costas com um braço só \\
\hline \multicolumn{2}{|l|}{ Com um braço ao longo do corpo } \\
\hline \multicolumn{2}{|l|}{ Abraçando a prancha } \\
\hline \multicolumn{2}{|c|}{$\begin{array}{l}\text { Segurando a prancha em cima dos joe- } \\
\text { Ihos }\end{array}$} \\
\hline \multicolumn{2}{|c|}{ Segurando no corrimão } \\
\hline \multicolumn{2}{|l|}{ Segurando o flutuador } \\
\hline \multicolumn{2}{|l|}{ Com espaguete } \\
\hline \multicolumn{2}{|l|}{ Com as mãos na cabeça } \\
\hline \multicolumn{2}{|l|}{ Com o professor puxando } \\
\hline \multicolumn{2}{|c|}{ Peito } \\
\hline Membros inferiores & Membros superiores \\
\hline Com prancha & Apenas braçada de peito \\
\hline
\end{tabular}

Fonte: Elaborado pelos autores, 2019.

Além das atividades descritas na Tabela 2, foram encontradas técnicas que mesclavam dois estilos: duas braçadas de crawl com um braço, duas braçadas de costas com o outro braço; perna virando de decúbito ventral para dorsal e vice-versa, e três braçadas de crawl, três braçadas de costas. Ainda dentro das técnicas de nado, exercícios de saltos em ponta (da borda da piscina e do bloco de partida).

\section{Atividades lúdicas}

Foram observadas como atividades lúdicas: tempo livre, desafios, brincadeiras e sessões historiadas. Alguns professores determinavam os cinco minutos finais de cada aula para tempo livre. Esse momento não era guiado pelos professores, e os alunos, na maioria das vezes, tinham materiais livres para explorar, como brinquedos e colchões flutuantes. Nos desafios, os alunos eram instigados a superarem-se em habilidades aquáticas como o mergulho. Desafios que foram observados nas aulas: passar por de baixo de espaguetes e de colegas; passar por dentro de arcos; executar cambalhotas; ficar embaixo d'água (bloqueio respiratório voluntário) e alcançar o espaguete enquanto o professor puxa. As brincadeiras não aconteciam com frequência, apenas 15 vezes em todas as observações de todas instituições, porém a mais frequente foi a "caça ao tesouro", em que os alunos buscavam objetos no fundo da piscina (argolas). Além dessa, foram observadas: pega-pega; falar embaixo d'água; marco-polo; tubarão; baleia voadora (o professor jogava os alunos para cima) e brincadeira competitiva de buscar materiais na superfície, em equipe "s". O professor "E" sempre fazia atividades de histórias contadas: com fantasia, contava situações e os alunos deveriam agir de acordo com a história. Por exemplo, os alunos fizeram uma "sopa mágica", e se relacionavam com a água de diversas formas: mergulhando, assoprando, batendo braços e pernas, etc.

Nados alternativos

Os nados combinados foram os mais presentes como nados alternativos, e apareceram em apenas duas aulas, ambas do professor "D". Como exemplos: braçadas de peito com per- 
nadas de crawl, braçadas de costas com ondulação e braçada de golfinho com perna de peito. Além disso, o professor " $G$ " propôs uma atividade de deslocamento em decúbito dorsal apenas fazendo movimentos de abdução e adução de pernas e braços.

Habilidades aquáticas gerais

O professor " $\mathrm{H}$ " foi o único que não trabalhou habilidades aquáticas gerais em nenhuma de suas aulas. Atividades de cambalhotas, flutuação, imersão (mergulho), sustentação e equilíbrio foram observadas nas aulas dos professores, sendo a primeira a mais frequente. Os exercícios de cambalhota, na maior parte das vezes, eram realizados por meio de desafios. Ainda, seguidos por deslocamentos do nado crawl, como por exemplo: quatro braçadas de crawl e uma cambalhota. Cinco dos oito professores trouxeram a cambalhota para suas aulas. Como atividades de flutuação, foram realizadas: "estrela do mar" - crianças flutuam em decúbito ventral, com braços e pernas afastados; "estrela do céu"- crianças flutuam em decúbito dorsal, com braços e pernas afastados e bola ou medusa - crianças flutuam em posição grupada.

Desafios de tentar tocar partes do corpo no fundo da piscina foram realizados como forma de praticar o mergulho. Além disso, o "canguru estático", em que os alunos devem mergulhar flexionando os joelhos e empurrar o chão subindo o mais alto possível, também foi praticado. Essas atividades estiveram presentes em aulas de um dos oito professores observados, sendo este o professor "E". Dois professores trabalharam a sustentação, sendo o "E" e o "G". As formas trabalhadas foram: tentar se sustentar na superfície sem o auxílio de qualquer material ou ajuda externa; e tentar girar em torno de si mesmo nos sentidos horário e antihorário, em posição horizontal, que também está associada ao equilíbrio. O professor "D" propôs que os alunos sentassem em pranchas e tentassem se deslocar sem cair. Essas duas atividades foram as únicas que trabalharam o equilíbrio.

Outros esportes aquáticos

O polo aquático e a natação artística foram os outros esportes aquáticos observados, ocorrendo duas vezes. O palmateio, que é uma técnica de sustentação e propulsão utilizada tanto no polo aquático quanto na natação artística, apareceu em uma aula do professor "D". Além do palmateio, o mesmo professor fez um jogo com bola e goleira em que os alunos estavam separados em duas equipes e deveriam tentar fazer o gol lançando a bola com as mãos. $\mathrm{Na}$ ação de extensão universitária dos professores "F", "G" e "H", os alunos tiveram o "dia livre” e, por conta própria, jogaram queimada.

Deslocamentos variados

Canguru, deslize, mergulhos com deslocamento e outros foram os deslocamentos variados observados. O canguru (saltos verticais consecutivos) e o deslize estiveram presentes em muitas aulas, nove cada um, e apenas o professor "C" não se apropriou dessas duas possibilidades. O deslize aconteceu tanto em posição de "streamline", com um braço à frente e o outro ao longo do corpo quanto com os dois braços ao longo do corpo. Mergulhos com deslocamentos variados estiveram presentes em 12 das 36 aulas observadas e todos os professores usaram. Além desses, verificou-se deslocamento em nado "cachorrinho", deslocamento em ondulação, deslocamento em cima do espaguete e caminhada equilibrando um objeto na cabeça. 
Características gerais e estratégias de ensino

Todas as aulas foram realizadas em piscinas cobertas e aquecidas, de, no máximo, 25 $\mathrm{m}$ de comprimento. Com exceção da turma do professor "D", as aulas aconteceram perto da borda da piscina, e continham um corrimão (barra) de auxílio à sustentação. Na maioria dos casos, os alunos entravam na piscina para começar a aula utilizando a escada. Porém, observou-se algumas aulas em que a entrada era livre ou fazendo salto em ponta. Diversos materiais foram utilizados pelos oito professores, sendo o professor " $D$ " o que mais os utilizou: 10 materiais em seis aulas. Em todas as aulas de todos os professores, os seguintes materiais foram utilizados: pranchas, argolas, brinquedos (bonecos), nadadeiras, flutuador estilo "pullbuoy", colchão, redutores de profundidade, espaguetes, bola, goleira, palmares e arcos. Apesar de um dos professores ter utilizado 10 materiais em seis aulas, o mesmo tinha a tendência de utilizá-los de forma alternativa. Por exemplo, utilizava pranchas para os alunos equilibrarem no corpo enquanto se deslocavam. Com exceção de duas turmas, as outras eram ministradas por apenas um professor. As aulas eram ministradas com os professores dentro d'água junto aos alunos, exceto pelo professor "C".

Os professores se comunicavam de forma lúdica e em linguagem compreensível para as crianças, de forma a garantir uma melhor aproximação com os alunos. Outro aspecto observado é que os professores sempre acompanhavam seus alunos, demonstrando e tocando-os. O professor "E" questionava as percepções e sensações dos alunos nas atividades e, além disso, solicitava aos alunos que realizassem as atividades com ou sem óculos de natação. Quando os professores foram questionados quanto aos objetivos das aulas, a aprendizagem do esporte foi a resposta mais enfatizada. Apesar disso, alguns demonstraram interesse na independência do aluno no meio aquático. Apenas um professor citou questões comportamentais como resposta.

\section{Discussão}

O objetivo central deste estudo foi identificar e analisar as atividades realizadas na iniciação de crianças à natação. Apesar das entrevistas manifestarem o interesse dos professores em trabalhar questões de afinidade com o meio aquático e fazer com que o aluno se sentisse confortável para se expressar e se locomover de forma independente, nas aulas observadas isso raramente aconteceu. Percebe-se ainda a predominância das práticas de ensino restritas a repetições de gestos técnicos exclusivos dos estilos de nado, o que demonstra uma dissociação entre natação e habilidades básicas para locomoção aquática. As exceções observadas foram as aulas do professor "E", que assumiu a condução das tarefas e desafios por meio de jogos simbólicos, visando criar envolvimento por parte das crianças e maior sucesso na realização das atividades (Tabela 1, professor "E"). Durante as aulas observou-se alunos que apresentavam ótima técnica de nado, porém não conseguiam mergulhar até o fundo da piscina para buscar materiais. Nessas aulas, aconteciam muitos exercícios analíticos de pernada e braçada segurando no corrimão da piscina. Tais evidências apontam para a necessidade de repensar o ensino da natação, ampliando o conceito de "saber nadar" (QUAN et al., 2015).

A pedagogia da natação necessita de uma visão que não se baseie apenas no cumprimento de tarefas e técnicas "corretamente" executadas. Deve-se criar condições de interação do aluno com a água, por meio de atividades que privilegiem a consciência do movimento na água para além do deslocamento perfeito. Portanto, o aprendizado da técnica deve ser indissociável ao desenvolvimento da relação com o meio aquático. O nado $\mathrm{crawl}$ foi o que apresentou maior predominância, o que condiz com a literatura já que é o nado mais frequente em eventos competitivos (REIS, 1987). Porém, nesta pesquisa foi constatado que após o nado 
crawl, o próximo nado a ser trabalhado é o nado costas, e não o peito, como salienta Langendorfer (2013).

Assim como o nado crawl teve predominância nas atividades de técnica, o "tempo livre" teve para as atividades lúdicas. Nos momentos "livres", alguns alunos demonstravam dificuldade em encontrar formas de deslocamento diferentes dos nados crawl e costas, pois eram praticamente as únicas vivências que tiveram. Conforme Selau (2000) salienta, a atividade lúdica na água é considerada uma atividade secundária, sem valor pedagógico, que ocupa menos de um terço da aula.

Observou-se também o interesse das crianças por experimentarem possibilidades de movimento do próprio corpo ao interagir com o meio. Alguns alunos demonstraram, nos momentos "livres", habilidades aquáticas que nos períodos de atividade dirigida não eram perceptíveis, reforçando assim o valor pedagógico do tempo livre e da livre exploração como meio de solução de problemas motores no contexto de aprendizagem dos esportes (LIGHT; WALLIAN, 2008).

O trabalho de nados alternativos, além dos quatro convencionais ( $\mathrm{rawl}$, costas, peito e golfinho), não foi identificado de modo sistemático. Apenas um professor trouxe os nados combinados para as suas aulas. Todo deslocamento que se distancia da ideia dos nados competitivos é praticamente recusado pelos professores, entretanto, quando se muda o repertório da tarefa que o aluno está acostumado a realizar, há um novo desafio à aprendizagem. Como mostra Newell (1986), modificações na tarefa levam o indivíduo a um novo estado organizacional, alterando a coordenação e os padrões de movimento. Foi justamente desta forma que o nado borboleta foi criado, quando o padrão de movimento do nado peito foi alterado (WALLECHINSKY, 1984).

As habilidades aquáticas gerais são mais notáveis nas aulas a partir de exercícios de cambalhotas. Ainda assim, na maioria das vezes, estiveram vinculadas à prática do nado $\mathrm{cra}$ $w l$. Portanto, constata-se que o objetivo dos professores em trabalhar esta habilidade não é com o objetivo de desenvolver domínio do meio aquático, mas sim para auxiliar a aquisição dos nados competitivos, apresentando alta relação com a aprendizagem da virada olímpica. Exercícios de flutuação e sustentação apresentaram baixa frequência nas aulas. Tais exercícios são importantes para (i) gerar conforto e estabilidade dos alunos e, posteriormente, (ii) ensinar os deslocamentos sob técnicas formais. Essa deficiência na flutuação/sustentação acaba prejudicando a excelência dos nados convencionais. Esperava-se uma maior frequência das habilidades aquáticas gerais, visto que impulsionam o desenvolvimento técnico dos nados, conforme observa Langendorfer (2013). Aprender a sustentar-se, trocar a posição do corpo em diferentes direções e equilibrar-se em variadas circunstâncias são excelentes formas de anteceder o ensino dos nados competitivos (FREUDENHEIM; GAMA; CARRACEDO, 2003). Tais habilidades precisam ser vistas como fundamentais para o desenvolvimento de independência no meio aquático.

Em aulas de iniciação à natação, atividades de adaptação são - ou deveriam ser - priorizadas (FERNANDES; LOBO DA COSTA, 2006). A aprendizagem de elementos de outros esportes aquáticos é um sistema que agrega este requisito, porém, neste estudo, constatou-se escassa regularidade nas aulas. Apenas um dos professores trabalhou palmateios e ainda, de forma pouco orientada (os alunos sentavam em pranchas e deveriam deslocar-se utilizando os braços). O polo aquático chegou perto em uma das 36 aulas observadas, quando o professor sugeriu um jogo de acertar a bola no gol. Na ação de extensão da universidade, o último dia de observação aconteceu no "dia livre". Uma vez por mês os alunos têm o período relativo a uma aula inteira para desempenharem as atividades que apresentam maior interesse. Foi nesse momento que eles se aproximaram mais de outros esportes aquáticos, pois utilizavam bolas e montavam estruturas com materiais alternativos para se deslocarem. Esse momento também é 
importante para o desenvolvimento de habilidades que não são, ou são pouco desenvolvidas na natação, como a percepção espaço temporal.

Canossa et al. (2007) e Castro, Correia e Wizer (2016) intensificam a afirmação da necessidade de um ensino que contemple múltiplos e diversos movimentos no meio aquático, e não apenas as técnicas dos quatro estilos competitivos nas aulas de natação. Além de praticar elementos de outros esportes aquáticos, realizar deslocamentos variados faz com que o aluno enfrente novas situações e tenha uma maior compreensão das forças do meio, o que auxilia na aquisição de novas formas de equilíbrio, sustentação e propulsão. Deslizes e mergulhos demonstraram-se como as principais formas de deslocamento além da propulsão de pernas e braços dos quatro estilos convencionais. Propostas diferenciadas de deslocamento na água, como desafiar os alunos a se deslocarem utilizando apenas membros superiores ou inferiores, com a cabeça fora d'água, com um pé fora d'água, apenas submerso, se deslocarem sentados em uma bola, e carregando algum material de forma alternativa aumentam a experiência de movimento e do repertório aquático.

Assim, priorizar o ensino multidisciplinar da natação é essencial para uma concepção metodológica que visa a habilidade aquática além de gestos técnicos da natação competitiva. Logo, esta concepção metodológica tem como fim propiciar aos indivíduos condições para que consigam ter a total independência no meio aquático, saibam se deslocar e gerar propulsões de diferentes formas, que realizem técnicas tanto de natação quanto de nado sincronizado e polo aquático, e sustentem-se sem auxílio de materiais e outras pessoas.

\section{Considerações finais}

Após o mapeamento, conclui-se que uma concepção para além dos quatro estilos não faz parte da metodologia encontrada nos espaços investigados (escola privada, ação de extensão de uma universidade, projeto social e clube). Para que os professores proporcionem uma maior relação/domínio do meio aquático aos seus alunos, as técnicas de nado não podem ser o único tópico trabalhado, mas sim junto a todos os outros, de forma equilibrada. Há a necessidade de um olhar integrativo de outras opções de aprendizagem na natação além do ensino técnico. A partir dos dados levantados, vemos uma urgência na necessidade de propostas metodológicas que busquem oferecer aos alunos práticas que expandem a interação com a água, buscando o desenvolvimento de habilidades básicas para crianças que estão começando sua experiência aquática.

\section{Referências}

BURKHARDT, Roberto; ESCOBAR, Micheli Ortega. Natação para portadores de deficiências. Rio de Janeiro: Ao Livro Técnico, 1985.

CANOSSA, Sofia; FERNANDES, Ricardo J.;CARMO, Carla; ANDRADE, Antonio; SOARES, Susana M. Ensino multidisciplinar em natação: reflexão metodológica e proposta de lista de verificação. Revista Motricidade, v. 3, n. 4, p. 82-99, 2007.

CASTRO, Flávio Antônio; CORREIA, Ricardo; WIZER, Rossane. Adaptação ao meio aquático: características, forças e restrições. In: MOURAÇO, Pedro; BATALHA, Nuno; FERNANDES, Ricardo J. Natação e atividades aquáticas: pedagogia, treino e investigação. Portugal: Instituto Politécnico de Leiria, 2016. p. 13-26. 
FERNANDES, Josiane Regina Pejon; DA COSTA, Paula Hentschel Lobo. Pedagogia da natação: um mergulho para além dos quatro estilos. Revista Brasileira de Educação Física e Esporte, v. 20, n. 1, p. 5-14, 2006

CATTEAU, Raymond; GAROFF, Gérard. O ensino da natação. São Paulo: Editora Manole LTDA, 1990.

FREUDENHEIM, A. M.; GAMA, R. I. R. de B.; CARRACEDO, V. A. Fundamentos para a elaboração de programas de ensino do nadar para crianças. Revista Mackenzie de Educação Física e Esporte, v. 2, n. 2, p. 61-69, 2003.

LANGERDORFER, Stephen. Which Stroke First? International Journal of Aquatic Research and Education, v. 7, n. 4, 2013

LANGENDORFER, S.; BRUYA, L. Aquatic readiness: Developing water competence in young children. Champaign, Illinois: Human Kinetics, 1995.

LIGHT, R.; WALLIAN, N. A. Constructivist-Informed Approach to Teaching Swimming. Quest, v.60, p. 387-404, 2008.

NEWELL, K. M. Constraits on the development of coordination: Motor Development in Children, aspects of coordination and control. Dordrecht: Martinus Nijhoff, p. 341- 360, 1986.

QUAN, L.; RAMOS, W.; HARVEY, W.; KUBLICK, L.; LANGENDORFER, S. J.; LEES, T. A.; FIELDING, R. R.; DALKE, S.; BARRY, C.; SHOOK, S \& WERNICKI, P. Toward Defining Water Competency: An American Red Cross Definition. International Journal of Aquatic Research and Education, v.9, n.1, p. 12-23, 2015.

REIS, Jayme Werner dos. Exercícios e habilidades aquáticas. Porto Alegre: D.C.Luzzatto Editores LTDA, 1987.

RIBEIRO, J. A. M. Análise hidrodinâmica do arrasto passivo e activo nas diferentes técnicas de nado. 2006. Monografia. Porto, 2006.

SANTOS, Ana Cristina; PEREIRA, Ruben Gonçalves. Estudo comparativo da organização das escolas de natação: três casos versus três parâmetros do processo ensino-aprendizagem. Revista de Desporto e Saúde da Fundação Técnica e Científica do Desporto, p. 87-93, 2008.

SILVA, L M; GIULIANO, A F; CASTRO, F A. Ensino, aprendizagem e avaliação da técnica do eggbeater em aulas de natação. Revista Brasileira Ciência e Movimento, p. 138-145, 2016.

SELAU, B. O comportamento lúdico infantil em aulas de natação. Movimento, n. 13, p.52$60,2000$.

XAVIER FILHO, E.; MANOEL, E.J. Desenvolvimento do comportamento motor aquático: implicações para a pedagogia da natação. Revista Brasileira de Ciência e Movimento, Brasília, v.10, n.2, p.85-94, 2002.

WALLECHINSKY, David. The Complete Book Of The Olympics. 1984. 
Recebido em: 12/03/2018

Revisado em: 29/11/2018

Aprovado em: 15/12/2018

Endereço para correspondência:

souza.castro@ufrgs.br

Flávio Antônio de Souza Castro

Universidade Federal do Rio Grande do Sul

Escola de Educação Física, Fisioterapia e Dança

Rua Felizardo, 750.

Jardim Botânico,

90690-200. Porto Alegre, RS. 